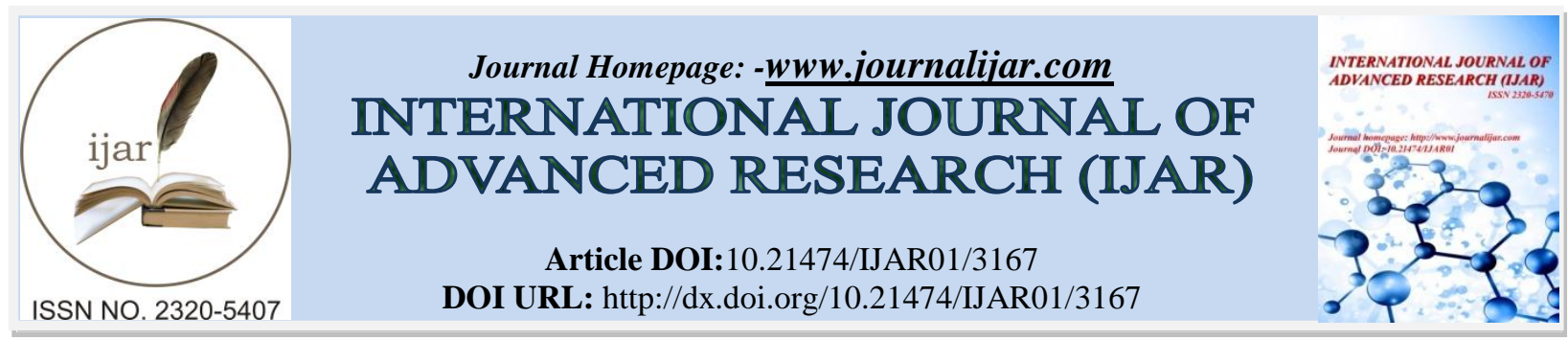

RESEARCH ARTICLE

\title{
THE PREVALENCE OF ANTIBIOTICS MISUSE AMONG SENIOR MEDICAL STUDENT AT UMM AL- QURA UNIVERSITY FACULTY OF MEDICINE, MAKKAH.
}

AmerAlboush MBBS, Matooq Noah MBBS, Mohammed Alfageah MBBS, JehadAlbitar MBBS,

\section{Manuscript Info}

Manuscript History

Received: 04 Decmber 2016

Final Accepted: 07 January 2017

Published: February 2017

\section{Abstract}

Misusing of antibiotics has been increasing in our society especially with easy access and the deregulations from the authority of selling antibiotics without medical prescriptions. With the misusing of the antibiotics, the resistance increased in our community and hospitals.

Many reasons had led us to this problem other than the easy access to the antibiotics, lack of education from health caregiver, stop antibiotic when feeling better, using leftover antibiotics, using antibiotics in viral illness such as upper respiratory tract infection.

The aim of this study is to evaluate the awareness of misusing antibiotics in the senior medical student at Umm Alqura University.

This study is a cross-sectional study was done in march 2016 to October 2016, and a total number of 170 of senior medical student males and females participate in this study and it showed female were the higher percentage in using the antibiotics, $69 \%$ of abused drug in female was Augmenting.

Copy Right, IJAR, 2017,. All rights reserved.

\section{Introduction:-}

Antimicrobial resistance a drug become less powerful against some type of microorganism which makes treating the infectious disease more challenging and increasing in the mortality from infectious disease [1,2]. 2 million people acquire infections with resistance bacteria that are resistant to one or more of the antibiotics that developed to treat that infection and 23,000 people annually dies as result of antibiotic resistant in the United States [11]. Most of these infections are a common organism and this what makes the problem more serious. As we can see the number is really high and it has been increasing recently and it consider as a global health issue [2]. There are many reasons behind this antibiotic resistance but the main reason is misusing OTC antibiotic and self-medication with the lack of medical background $[4,6,7]$ other reasons like saving time and money, feeling better with same antibiotics in a previous illness, leftover medicine available [12]

The prevalence of antibiotic misuse seems to be much higher in developing countries and it's increasing more and more comparing to the developed countries, which have more strict rules when it comes to prescribing antibiotics, and making the only way to get antibiotics is with medical prescription [10][3]. It has been estimated that tow third of antibiotics that people take orally is misused and shouldn't be taken [5].

The aim of this study is to assess the antibiotic misuse and to evaluate the awareness of the medical student when it comes to deal with over the counter antibiotics in Umm Alqura University Makkah Saudi Arabia 


\section{Method:-}

This is a cross-sectional study was done on senior medical student males and females at Umm Alqura University, with a sample size (170), calculated by ROASOFT, sample size calculator with a 5\% margin of error, $95 \%$ confidence level and $50 \%$ response distribution.

Data was collected through an online questionnaire using Google survey.

SPSS software (version 21) was used for data analysis and P value less than 0,05 used for significance, the chisquare used to assess the association between variables.

Approval of the ethical committee and the student consent to participate in this study has been taken.

The aim of this study measures the prevalence of antibiotics misuse among senior medical student in Umm Alqura University.

The study was a self-funding study.

\section{Result:-}

Among 170 of senior medical student males and females participants ( 85 males and 85 Females). The total percentage of antibiotic misuse was $10.58 \%(n=170)$ of all participants. Regarding of the gender, the higher proportion of female senior medical student misuses the antibiotic when compared to male. And the augmenting where is the most used antibiotic $66.3 \%$

The results showed the percentage of antibiotic were show height percentage in female by $69 \%$ figure (1).

\section{FIGURE 1}

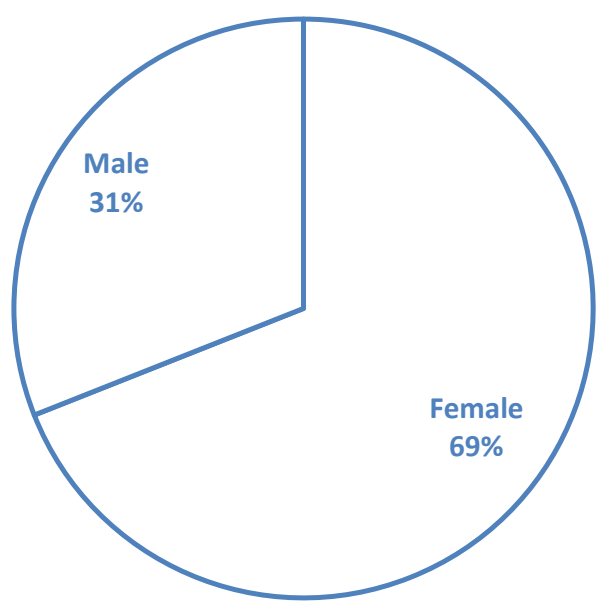


The results shows the percentage of the most antibiotic used was be Augmentin by $66.3 \%$ figure (2).

\section{FIGURE 2}

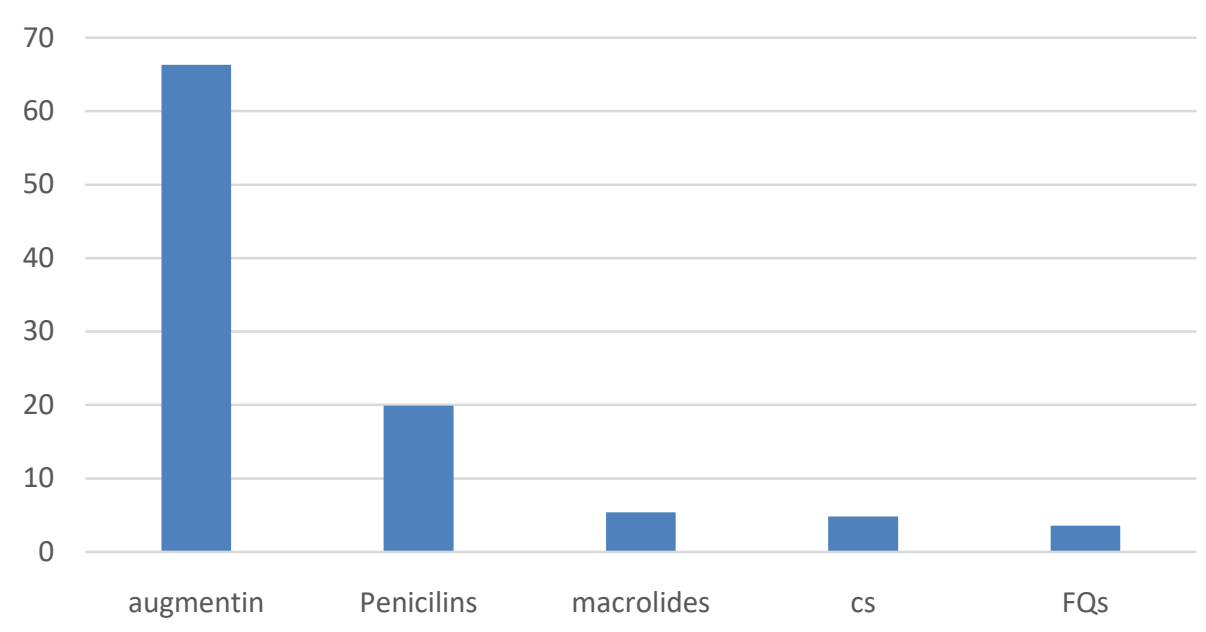

\section{CS:cephalosporin. FQs: fluoroquinolones}

\section{Discussion:-}

In this study we found that majority of participants were familiar with different types of antibiotic abuse, our finding agrees with general reports in different countries.

Based on high response rate from each group, it can be stated that the result obtained in this investigations are representative of the target population.

The results indicated that female was higher than male by $69 \%$ of the total participants, and we observed that the Augmentin was the highest antibiotic use among all antibiotic by $66.3 \%$.

In general, there are several limitations in this study, low sample size that may introduce nonresponsive bias. And this study may offer important exploratory findings for a senior medical student in Saudi Arabia. Future studies could attempt a different study design to gain more insight into factors contributing to antibiotic abuse.

\section{Conclusion:-}

The prevalence of antibiotic misuse among senior medical student in Makkah region considers high. Female misuse the antibiotic more frequently than male and the Augmentin is the most used. We recommend the creation of continued public health education about their side effect. Further investigation and studies could be conducted to assess the educational level and the awareness of their side effect. 


\section{Reference:-}

1. Scaioli G., Gualano M. R, Gili R., et al "Antibiotic Use: A cross-sectional survey assessing the knowledge, attitudes and practices amongst students of a school of medicine in Italy," PLOS ONE, vol. 10, no. 4. 2015.

2. J. O. Fadare and I. Tamuno, "Antibiotic self - medication among university medical undergraduates in Northern Nigeria," J. Public Heal. Epidemiol., vol. 3, no. 5, pp. 217-220, 2011.

3. E. E. Konozy, M. Ghaieth, S. M. Elhag, et al "Antibiotics self-medication among medical and nonmedical students at two prominent Universities in Benghazi City, Libya," J. Pharm. Bioallied Sci., vol. 7, no. 2, p. 109, 2015.

4. World Health Organization (2009) Medicines use in primary care in developing and transitional countries: Fact book summarizing results from studies reported between 1990 and 2006. World Health Organization. Available: http://apps.who.int/ medicinedocs/documents/s16073e/s16073e.pdf. Accessed 9 May 2013.

5. Okeke IN, Laxminarayan R, Bhutta ZA, et al (2005) Antimicrobial resistance in developing countries. Part I: recent trends and current status. Lancet Infect Dis 5: 481493.

6. Gannon J (2000) The global infectious disease threat and its implications for the United States. Washington: National Intelligence Council $52 \mathrm{p}$

7. Okeke IN, Klugman KP, Bhutta ZA, et al (2005)Antimicrobial resistance in developing countries. Part II:strategies for containment. Lancet Infect Dis 5: 568-580.

8. Okeke IN, Lamikanra A, Edelman R (1999) Socioeconomicand behavioral factors leading to acquired bacterial resistanceto antibiotics in developing countries. Emerg Infect Dis 5: 18-27.

9. Cebotarenco N, Bush P: Reducing antibiotics for colds and flu: a student-taught program. Heal Educ Res 2008, 23:146-157.

10. Huang S, Rifas-Shiman S, Kleinman K, et al: Parental knowledge about antibiotic Use: results of a clusterrandomized, multicommunity intervention. Pediatrics 2007, 119: 698-706. 10.1542/peds.2006-2600

11. Napolitano F, Izzo MT, Di Giuseppe G, et al: Public knowledge, attitudes, and experience regarding the use of antibiotics in Italy. PloS One. 2013, 8 (12): e84177-10.1371/journal.pone.0084177.

12. US Department of Human and Health Services, Centre for Disease Control and prevention. Antibiotic Resistance Threats in the United States. [Accessed August 25 2014];2013.

13. self-medication with antibiotics among non-medical university students of Karachi: a cross-sectional study. 